\title{
Principios para la identificación del diseño curricular de un sistema educativo opresor
}

Principles for the identification of the curricular design of an oppressive educational system

Princípios para identificar o desenho do currículo de um sistema de educação opressivo

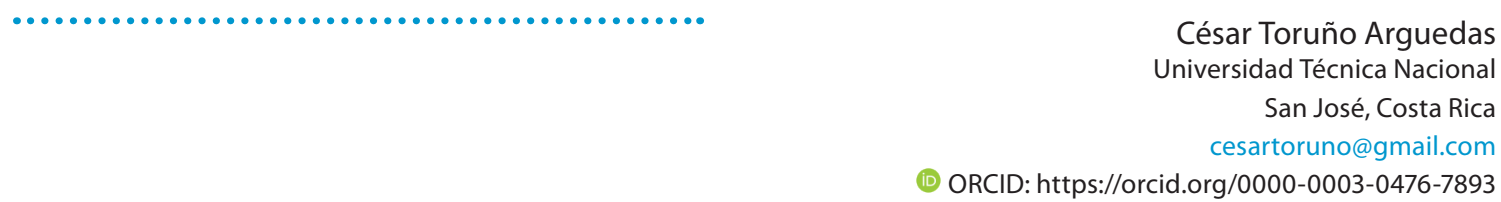

Recibido - Received - Recebido: 26 / 05/ 2021 Corregido - Revised - Revisado: 15 / 09 / 2021 Aceptado - Accepted - Aprovado: 21 / 10 / 2021

DOI: https://doi.org/10.22458/ie.v23i35.3464

URL: https://revistas.uned.ac.cr/index.php/innovaciones/article/view/3464

\begin{abstract}
Resumen: En la teoría, los sistemas educativos tienen por objetivo la formación de una ciudadanía que integre acciones y compromisos sociales con el desarrollo de su bienestar personal; sin embargo, en la práctica asistimos a situaciones educativas contrarias a dicho objetivo que provocan, en el mejor de los escenarios, una debilidad formativa y, en el peor de los casos, la constitución de un esclavo en tiempos modernos que abdica de la necesidad de cadenas físicas para someterse a cadenas intelectuales, culturales, sociales y económicas. Por este motivo, y como una propuesta crítica que pretende alertar de la complicidad en este escenario por parte de los diseños curriculares, este ensayo realiza una discusión conceptual sobre currículo, pedagogía crítica y el contexto del diseño curricular para, posteriormente, proponer unos principios curriculares para la implementación y consolidación de un sistema educativo opresor como forma de analizar y cuestionar la práctica del diseño curricular. La elaboración de los principios del diseño curricular permite analizar, desde la pedagogía crítica y la ruptura del discurso técnico dominante en esta área, la existencia de prácticas manifiestas en la estructura curricular que requieren ser cuestionadas y transformadas en el marco de un objetivo de desarrollar sistemas educativos democráticos.
\end{abstract}

Palabras clave: educación, educación universitaria, currículo, diseño curricular, gestión educacional.

Summary: In theory, educational systems have as their objective the formation of a citizenship that integrates actions and social commitments with the development of their personal well-being. However, in practice, we are witnessing educational situations contrary to this objective that provoke, in the best of scenarios, a formative weakness and, in the worst of cases, the constitution of a slave in modern times who abdicates the need of physical chains to submit to intellectual, cultural, social and economic chains. For this reason, and as a critical proposal that aims to warn of the complicity in this scenario on the part of the curricular designs, this essay carries out a conceptual discussion on the curriculum, critical pedagogy and the context of the curricular design. Later, it proposes some curricular principles for the implementation and consolidation of an oppressive educational system as a way to analyze and question the practice of curricular design. The development of the principles of curricular design allows the analysis, from a critical pedagogy and the rupture of the dominant technical discourse in this area, of the existence of manifest practices in the curricular structure that need to be questioned and transformed within the framework of the goal of developing democratic educational systems.

Key Words: education, university education, curriculum, curriculum design, educational management.

Resumo: Em teoria, o objetivo dos sistemas educacionais é a formação de uma cidadania que integre ações e compromissos sociais com o desenvolvimento de seu bem-estar pessoal; porém, na prática, estamos presenciando situações educacionais contrárias a este objetivo que conduzem, no melhor dos cenários, a uma precária formação e, no pior dos casos, à constituição de um escravo nos tempos modernos que abdica da necessidade de cadeias físicas para se submeter às cadeias intelectuais, culturais, sociais e econômicas. Por esta razão, e como uma proposta crítica que visa alertar sobre a cumplicidade neste cenário por parte da concepção curricular, este ensaio realiza uma discussão conceitual sobre currículo, pedagogia crítica e o contexto da concepção curricular a fim de, posteriormente, propor alguns princípios curriculares para a implementação e 
consolidação de um sistema educacional opressivo como forma de analisar e questionar a prática do desenho concepção curricular. A elaboração dos princípios de desenho curricular nos permite analisar, a partir da perspectiva da pedagogia crítica e da ruptura do discurso técnico dominante nesta área, a existência de práticas manifestadas na estrutura curricular que precisam ser questionadas e transformadas dentro da estrutura do objetivo de desenvolvimento de sistemas educacionais democráticos.

Palavras-chave: educação, educação universitária, currículo, desenho de currículo, gestão educacional.

\section{INTRODUCCIÓN}

Durante las últimas décadas, tanto la pedagogía crítica como sectores progresistas críticos de la sociedad civil exigen transformaciones al sistema educativo y del currículo en particular (Gimeno, 2010) para superar la pedagogía por objetivos (Gimeno, 1997) como enfoque en los diseños curriculares.

Como bien ha establecido Magendzo (2008, p. 20), "la globalización, la sociedad del conocimiento y la construcción de sociedades más democráticas influyen y tienen consecuencias en el diseño y elaboración del currículum". Ante estas demandas de transformación, los enfoques técnico y práctico del currículo han presentado falencias y limitaciones estructurales para ofrecer escenarios de cambios sustantivos.

En el anterior escenario, desafíos como la educación para la libertad, convivencia, desarrollo integral del ser humano, pensamiento crítico, transformación personal y social, eliminación de prejuicios, supresión de la violencia física, económica y sociocultural eran desatendidos en los diseños curriculares nacionales con excepción de las propuestas producidas desde la pedagogía crítica.

De la pedagogía crítica han surgido propuestas epistémicas y parcialmente metodológicas para la liberación de estudiantes-docentes (Freire, 2015a, 2015b, 2012, 2008, 2006, 2005a, 2005b, 2005c, 2004, 2001, 1977), debates curriculares (Gimeno, 2010a, 2010b, 2001, 2000, 1997), Giroux (2006, 2003, 1997, 1990), Giroux y McLaren (1998), Kemmis (1998), Torres (1998) y debates evaluativos (Santos, 2003, 1999, 1995). Como complemento a estas líneas reflexivas, el presente ensayo se elabora a partir de la investigación del autor en pedagogía crítica y su experiencia en el diseño curricular de programas de estudio preuniversitario y planes de estudio en la educación superior.

El ensayo tiene por objetivo la elaboración de premisas o principios de un currículo que favorece la opresión de las personas como mecanismo académico para evidenciar la necesidad de repensar y transformar los diseños curriculares. Por tanto, la importancia del presente texto radica en la posibilidad de visibilizar las premisas del diseño curricular que favorecen la constitución de un sistema educativo opresor, un insumo innovador en el debate curricular y facilitador de posibilidades de transformación de las prácticas y productos curriculares.

Para alcanzar el objetivo del ensayo, se realizará una aproximación teórica al contexto educativo (sociedad, cultura y economía) así como al currículo desde una percepción crítica. Posteriormente, se describirán los principios para el diseño curricular de un sistema educativo opresor en las dimensiones de estructura curricular propuestas por Toruño (2020a), a saber: estudio de viabilidad, justificación, fundamentación teórica, misión, visión, objeto de estudio, perfiles, objetivos o propósitos generales y específicos, malla curricular, áreas, ejes; así como programas de los cursos y la contextualización curricular.

\section{DESARROLLO DEL TEMA}

Una constante en los análisis de los sistemas educativos es la interacción con la sociedad y la diversidad de intereses que proyectan o, al menos, tratan de proyectar sus agendas en la estructura educativa. A nivel occidental, la pedagogía crítica ha realizado extensos análisis sobre los intereses del sistema capitalista en la educación, ya que el capitalismo tiene por objetivo "la construcción del ser humano disciplinado, 
obediente y acrítico en relación al modelo de sociedad y los poderes establecidos [generando] una ética del trabajo acorde con las necesidades de la sociedad capitalista naciente" (Torres, 2001, p. 185), individualista, competitivo y eficiente.

El proyecto capitalista se manifiesta en un proyecto hegemónico explícito o implícito (dentro del currículo oculto definido por Torres, 1998) asociado, en su etapa inicial, con el uso de premisas administrativas, organizativas y evaluativas de las empresas industriales en la estructura educativa. Este fenómeno se consolidaría con la propuesta de un currículo técnico expuesto por Tyler (1973) al finalizar la primera mitad del siglo XX. Este enfoque técnico y la correspondiente pedagogía por objetivos "nace al amparo del eficientismo social que ve en la escuela y en el currículo un instrumento para lograr los productos que la sociedad y el sistema de producción necesitan en un momento dado" (Gimeno, 1997, p. 10).

Según Escudero (2000), este currículo técnico alcanzaría como características esenciales la organización por objetivos, la inclusión de fundamentos para la selección de objetivos, la organización secuencial y estructurada del aprendizaje y, finalmente, la inclusión de una evaluación sistematizada y planificada. Gimeno (1997) aporta una lectura crítica integral del currículo técnico por las repercusiones en la estructura administrativa y pedagógica y en la contextualización curricular, con énfasis en el rol docente como técnico aplicador.

A raíz de las transformaciones políticas, económicas, culturales y científicas posteriores a la Segunda Guerra Mundial, el sistema educativo comenzó a sufrir el primer gran desfase entre necesidades contextuales y su capacidad de respuesta. Por este motivo, 20 años después de la propuesta de Tyler, Taba (1974) ajustaría el diseño curricular a las necesidades de la Revolución Científica Tecnológica y el mundo occidental durante la Guerra Fría. La propia Taba reconocía que la "revisión del currículo proviene de los cambios drásticos en la tecnología y la cultura, que van desde la mecanización hasta la energía atómica, las demandas insaciables de la industria en expansión de la mano de obra inteligente" (Taba, 1974, p. 15).

En su propuesta curricular, Taba (1974) mantiene las premisas de Tyler (1973) pero da forma a la estructura que dominará el diseño curricular hasta nuestros días, a saber: diagnóstico, objetivos, selección de contenido, organización de contenido, actividades de aprendizaje, organización de la mediación y actividades-instrumentos de evaluación. Esto es cuestionado por Gimeno (1997, p. 10), en tanto el diseño aspira a

lograr diseños o programaciones muy estructuradas del proceso de enseñanza-aprendizaje, la intención de lograr el que cada uno de esos diseños se ajuste a objetivos específicos, la huida de la ambigüedad, de los objetivos no formulados en esos términos, la obsesión por el cómo formularlos, la búsqueda de la eficacia mensurable de los tratamientos pedagógicos que persiguen esos diseños ajustados.

El diseño curricular esbozado por Tyler y Taba mantendrá una vigencia práctica en los currículos occidentales hasta nuestros días; sin embargo, a partir de la década de 1980 se desarrolla un segundo gran cisma entre las necesidades del contexto y las posibilidades de respuesta del sistema educativo; esto motivado por el final de la Guerra Fría y el ascenso del neoliberalismo desde los centros de poder británicos y estadounidenses.

En el caso de Latinoamérica, el avance neoliberal se consolida como respuesta de ciertos grupos dominantes a las crisis económicas de la década de 1970, las presiones económicas del Fondo Monetario Internacional y el Banco Mundial (Hinkelammert, 1999), el proyecto económico capitalista-neoliberal en algunos países latinoamericanos y los conflictos entre sectores dominantes durante la crisis del Estado de bienestar. 
El neoliberalismo implicó, a nivel curricular, el diseño de currículos a partir de una visión centrada en la libertada individual, la competencia y la valoración de lo material, insolidaria, promotora del darwinismo social, formadora de consumidores en vez de ciudadanos, trabajadores obedientes-eficientes, aceptación de las reglas del mercado y supresión de anhelos de libertad o pensamiento crítico (Toruño, 2010). Esto aunado a la visión neoconservadora de un ser humano vinculado con la "Familia, prevención del fracaso, eficiencia, miedo a la violencia y a las drogas, miedo al emigrante, derecho a elegir lo que cree uno que es más conveniente para sus intereses, ascenso individual, educación para el mercado de trabajo" (Gimeno, 1998a, p. 293), defensores de la democracia burguesa y sus instituciones, respetuosos de la autoridad y las leyes, etc.

En línea con lo anterior, el neoliberalismo es la ideología del mercado total (Vargas, 2002, pp. 26- 27), según la cual "la realidad -todos los aspectos de la realidad-son susceptibles de -y deseablemente han de quedar bajo- el control de la lógica mercantil, sujetos, pues, a los criterios propios del mercado capitalista y subordinados a objetivos de lucro". Su objetivo es realizar reformas a los Estado (destruir el Estado de bienestar o desarrollista) para adaptarlos a la transnacionalización económica e implantar una hegemonía neoliberal, en aspectos políticos y culturales, legitimadora de la racionalidad económica del sistema (Torres, 2001, p. 31). Por tanto, es antiestatista y librecambista (Vargas, 2002) y protransnacionalización económica, así como impulsora de reformas educativas para aumentar la eficiencia (disminución de costos).

Desde las políticas neoliberales, se construye un currículo con un fundamento filosófico donde

la visión ontológica de ser humano es un consumidor contextualizado en una sociedad de mercado, bajo las reglas y demandas del libre comercio. Se le visualiza como un individuo en eterna competencia, lo que le impide (o le exige) deshabilitar lazos sociales, para poder ser competitivo en la lucha darwinista social; claro está, acrítico y apolítico para que pueda legitimizar los proyectos económicos-políticos de los grupos de presión económica nacional e internacional (Toruño, 2010, p. 17).

En el marco de la anterior reflexión, resulta necesario explicitar que el hecho de que para el presente ensayo se analice la vinculación entre el sistema educativo opresor y el sistema capitalista responde a las realidades socioeconómicas de nuestra región. No obstante, la construcción de un sistema educativo opresor no es exclusivo ni necesariamente vinculado a un proyecto capitalista (incluidas sus versiones como el neoliberalismo), en el tanto puede surgir en otros modelos económicos (por ejemplo, comunismo, socialismo o socialismos en versiones del siglo XXI), políticos (democracias, dictaduras, monarquías), culturales y sociales.

En este contexto, educar personas esclavas trasciende la concepción histórica de relación de poder y violencia de una persona "amo" sobre una o varias personas sometidas a un proceso para convertirlas en objetos carentes de rasgos y reconocimientos, como parte igualitaria de una comunidad. Al respecto, sigue vigente la premisa de Tyler (1973, p. 104) sobre que

si la escuela cree que su función primordial consiste en enseñar a la gente a adaptarse a la sociedad, pondrá el acento en la obediencia a las autoridades actuales, en la lealtad a las formas presentes y tradicionales, en la capacidad para desempeñar las técnicas exigidas por la vida de hoy pero, en cambio, si se prefiere la función revolucionaria de la escuela, se preocupará por el análisis crítico, la capacidad para resolver nuevos problemas, la independencia y la autonomía, la libertad y la autodisciplina

Educar esclavos y esclavas en tiempos modernos es la vivencia cotidiana de la "caverna" descrita por Platón, es educar a personas sometidas a un poder invisible (mercado, proyecto hegemónico, 
Estado, grupo de presión u otro) dentro de una realidad enseñada como única pero que oculta otras realidades posibles. Educar personas esclavas modernas exige generar un proceso de formación que elimine o disminuya voluntades, pensamiento crítico y hasta vínculos afectivos, que sustituya pilares de la humanidad para dar paso a la formación de un consumidor, sobreviviente cotidiano y un objeto incorporado a la revolución tecnológica.

Es importante indicar que educar esclavos y esclavas puede ser un proyecto sistematizado y estructurado por un "amo" o, como sucede en la mayoría de las situaciones educativas, es un producto multicausal realizado a partir de diseños curriculares, contextualización curricular y práctica educativa fuera del aula. Por este motivo, vale la pena comprender la importancia del currículo y la pedagogía crítica para contrarrestar este proceso de esclavitud, con la salvedad de que la pedagogía crítica es solo una de las posibles fuentes de conocimiento para la transformación de las practicas educativas y de los diseños curriculares.

Aunado a lo anterior, resulta necesario explicitar que el análisis de los sistemas educativos opresores (y sus respectivos diseños curriculares) debe contemplar, como lo establece la pedagogía crítica y la posición neomarxista, que existen posibilidades de resistencia por parte de quienes integran el sistema educativo. Es decir, no existe un proceso homogéneo y unidireccional; por el contrario, es un proceso heterogéneo que puede implicar resistencias y hasta transformaciones desde las comunidades educativas.

\section{Pedagogía crítica y currículo}

La pedagogía crítica es el área educativa que ha desarrollado como una respuesta transgresora, cuestionadora y promotora de cambios sustantivos del sistema educativo, con la premisa de que el aprendizaje trasciende un simple proceso psicológico para ser influido por elementos sociales, culturales, económicos, ecológicos, políticos, de género y otros. Su origen se encuentra en la vinculación de temas educativos con intelectuales marxistas, neomarxistas y de las escuelas críticas de pensamiento europeo.

Contrario a las tesis del marxismo clásico en educación, los neomarxistas incorporaron la premisa de que el sistema educativo era más que un sistema reproductor (Giroux, 2006), por lo que eran posibles las transformaciones de las realidades de resistencias conscientes o no, planificadas o no. Asimismo, se comprende al sistema educativo como un entramado de relaciones de poder y resistencias (Giroux y McLaren, 1998) que son objeto de análisis gracias a las metodologías y reflexiones de la pedagogía crítica (Cabello, 2003). Al respecto, Apple (1997, p. 32) afirma que

“La reproducción, el Estado, la legitimación, la acumulación, la contradicción, la hegemonía ideológica base/superestructura, son conceptos extraños a un terreno comprometido en la construcción de métodos eficaces y neutrales. Sin embargo, si queremos tomarnos en serio la naturaleza política de la educación y el currículum, así como los beneficios y resultados desiguales de la educación escolar, son esenciales".

Para alcanzar la transformación del sistema educativo, se requiere de personas docentes asumidas como "capaces de enfrentar cuestiones relacionadas con la función más amplia del currículum y de la escuela, así como manejar las relaciones entre cultura y poder" (Giroux y McLaren, 1998, p. 85), es decir, asumirse como intelectuales transformadores (Giroux, 1990). Asimismo, se requiere la transformación de las reflexiones, enfoques, metodologías e incluso de la forma en cómo se concibe el aprendizaje y la participación de estudiantes-docentes. Sobre estos elementos destacan las reflexiones de Freire (2015a, 2015b, 2012, 2008, 2006, 2005a, 2005b, 2005c, 2004, 2001, 1977) como pilares de una visión de transformación con miras a utopías, pero cimentada en las realidades diversas. 
Lo anterior ha derivado en un amplio y profundo debate sobre el papel del currículo dentro de las realidades reproductivas-transformadoras del sistema educativo, siendo referentes los aportes de la Escuela Española liderada por Gimeno (2010a, 2010b, 2001, 2000, 1997), Torres (1998) y Santos (2003, 1999, 1995), la Escuela Anglosajona con Giroux (2006, 2003, 1997, 1990), Giroux y McLaren (1998), McLaren (1997), Kemmis (1998) y Apple (1996a, 1996b y 1997).

A nivel curricular, la pedagogía crítica insta a "interrogarse acerca de los intereses a los que sirven los programas ofertados, quién tiene realmente acceso a estos programas, quién detenta el poder para efectuar cambios y cuáles son los resultados previstos, o imprevistos, de la manera en que está estructurada la educación y la enseñanza" (Cabello, 2003, p. 43), y con más relevancia en el marco de un proyecto neoliberal por cuanto "es preciso desenmascarar estos procesos sociales y ofrecer formas de acción social y política que presente modos de entendimiento y de lucha" (Kemmis, 1998, p. 125), con un currículo poseedor de "valores y supuestos que es preciso descifrar" (Gimeno, 1998b, p. 18) y con conciencia de que el currículo "constituye uno de los principales agentes en la introducción, preparación y legitimación de las formas de vida social" (McLaren, 1997, p. 55).

Lo anterior exige asumir la premisa de que quien gestione, diseñe e implemente el currículo debe superar el "analfabetismo conceptual y político" (Giroux y McLaren, 1998, p. 85) para incorporar elementos transformadores propuestos por Escudero (2000) vinculados con participación crítica de la comunidad educativa, el componente moral del currículo con respecto a la justicia social, desarrollo de centros educativos democráticos, análisis y acción de problemas del contexto, confrontación de la realidad política, e investigación como eje transversal del aprendizaje.

Por tanto, el diseño curricular requiere asumir un compromiso para responder en el siglo XXI y en plena vivencia de la tercera gran ruptura entre las necesidades de la sociedad (Cuarta Revolución Industrial Tecnológica) y las respuestas educativas, con especial atención a los dilemas socioeconómicos culturales del proyecto hegemónico capitalista (y su vertiente neoliberal) y el intento de invisibilización de las demandas de grupos de resistencia con temáticas desde la ecología hasta la protección de datos, pasando por garantías sociales, derechos individuales y formación integral. A partir de esta premisa, a continuación se expondrán los principios y características que guían el diseño curricular de un sistema cuyo objetivo es educar esclavos como una forma de denuncia del currículo-sistema educativo opresor.

\section{Principios para el diseño curricular de un sistema educativo opresor}

El currículo comprendido como área de conocimiento, proceso, producto procesado, práctica educativa, vivencia educativa, inesperado y reducido o formal (Toruño, 2020b) coincide, en una serie de etapas para el diseño y evaluación de la propuesta curricular: estudio de viabilidad, justificación, fundamentación teórica, misión, visión, objeto de estudio, perfiles, objetivos o propósitos generales y específicos, malla curricular, áreas, ejes (Toruño, 2020a), así como los programas de cursos y contextualización curricular.

En el marco de lo anterior, se expondrán los principios y las características básicas de un diseño curricular (las conceptualizaciones de las etapas pueden ser vistas en Toruño, 2020b), con la incorporación de las características o premisas necesarias para que el currículo favorezca un sistema educativo opresor; esto construido a partir de las premisas de la pedagogía crítica y el enfoque curricular crítico descrito en apartados previos. La propuesta de principios y características del currículo para un sistema educativo opresor favorecería que las personas curriculistas puedan contrastar estos elementos con los diseños curriculares realizados y, de este modo, prevenir y resistir propuestas curriculares que favorezcan la formación de personas esclavas en tiempos modernos.

1. Poder de toma de decisión. El primer paso para establecer un diseño curricular de un sistema educativo opresor se vincula con la concentración vertical de toma de decisiones sobre la estructura curricular (programas incluidos), evaluación y mejora. Resultará opresor aquel diseño en que: 
a. La verdadera toma de decisión se concentra en una o varias personas ajenas al diseño curricular.

b. La comisión de diseño curricular adquiere funciones técnicas o de coordinación, pero limita su accionar a los intereses del agente tomador de decisiones.

c. Solo algunas personas involucradas en el proceso de diseño curricular conocen a la persona o personas tomadoras de decisión.

2. Conformación la Comisión de Diseño Curricular. La conformación de la comisión facilita un sistema opresor si:

a. Se carece de criterios democratizadores para seleccionar quiénes participan en la comisión.

b. Integra solo a especialistas disciplinares (visión académica) y omite la participación de docentes, estudiantes, familias y grupos vinculados.

c. Presenta ausencia de especialistas en currículo y evaluación o estos especialistas tienen poca experiencia en procesos curriculares, débil formación y limitada experiencia en investigación.

3. Estudio de viabilidad. Este proceso permite recabar información de necesidades, realidades y expectativas sobre el currículo a desarrollar (con sus respectivos aprendizajes), por lo cual se favorece un sistema opresor si:

a. No se realiza un estudio de viabilidad.

b. Se prioriza información sobre necesidades de un único sector o grupo, omitiendo a la población estudiantil-docente, grupos diversos de la sociedad civil y sectores productivos.

c. Se diluye información objetiva en apreciaciones subjetivas de integrantes de la comisión.

d. El estudio se construye para justificar decisiones previamente tomadas.

e. Omite realidades socioculturales, económicas, políticas y otras vinculadas con la dinámica del ser humano como ciudadano de un Estado nación en era global.

4. Justificación. Integra aspectos de pertinencia, relevancia y calidad del diseño curricular desarrollado; manifiesta una propensión a un sistema opresor si:

a. Omite la innovación y revolución educativa como elementos de pertinencia, para centrar su argumentación en la continuidad de prácticas educativas vigentes (y cuestionadas).

b. Centra la pertinencia y relevancia en aspectos académicos y contenidos.

c. La relevancia se establece a partir de la demanda de un grupo o sector, omitiendo necesidades de otros grupos e integrantes de la sociedad.

d. Se omiten criterios de calidad o se establecen únicamente desde parámetros cuantitativos sobre aspectos no sustantivos del proceso de aprendizaje.

5. Fundamentación teórica. La fundamentación teórica curricular y disciplinar de la propuesta promovería un sistema educativo opresor si:

a. Omite referencias teóricas y reflexiones provenientes de la pedagogía crítica.

b. Omite referencias directas y reflexiones provenientes de autores referentes del constructivismo, socioconstructivismo y aprendizaje significativo.

c. Omite una fundamentación del currículo desde un enfoque crítico.

d. Centra la fundamentación en teorías y reflexiones disciplinares. 
e. Las reflexiones teóricas son débiles (evitan un debate profundo en el área disciplinar y curricular).

6. Misión y visión. La misión y visión de la propuesta curricular visibilizan un sistema educativo opresor cuando:

a. La redacción prioriza elementos académicos.

b. Se omiten elementos de una formación integral (individuales, socioculturales, económicos y otros).

c. Se visibiliza la priorización de las demandas o intereses de un sector productivo o social.

d. Las características indicadas no coinciden con los objetivos-propósitos, perfiles, malla y programas de los cursos.

7. Objeto de estudio. Un objeto de estudio se comprende "como el componente tangible o intangible sobre el cual se realizarán las acciones académicas, investigativas y de extensión social de la carrera" (Toruño, 2020a, p. 34); por tanto, promovería un sistema opresor si:

a. Solo prioriza un área de acción (académica, investigativa o extensión social).

b. Omite una diversidad de áreas o disciplinas que integran el proceso educativo.

8. Perfiles. Los perfiles son la referencia explícita del ser humano-profesional que saldrá al terminar el proceso educativo especificado en el currículo. En caso de optar por un sistema opresor, se visibilizará en:

a. Priorización de lo académico en el perfil.

b. Débil presencia de elementos de formación integral (individuales, socioculturales, económicos y otros) y de las áreas de investigación, extensión social, formación humanística y emprendedurismo.

c. Se priorizan las demandas o intereses de un sector productivo o social.

d. Las características indicadas no coinciden con los objetivos-propósitos ni con la malla.

e. No existe una vinculación clara entre los perfiles y los programas de los cursos.

9. Objetivos o competencias. Se puede manifestar un sistema educativo opresor si:

a. Presenta una polaridad en su redacción, a saber: ambigüedad que impide dar un seguimiento sistematizado o una especificación máxima que impide incorporar elementos cualitativos y emergentes.

b. Evidencia un sesgo hacia el control.

c. Manifiesta una visualización del aprendizaje como etapas o segmentos de un proceso de producción.

d. Prioriza una visión del aprendizaje vinculada con la acumulación de conocimientos o competencias.

e. Establece elementos sustantivos como pensamiento crítico, investigación, habilidades blandas u otras, pero de forma fracturada y manifiesta solo en un apartado.

f. Omite responder a los perfiles para establecer un modelo preestablecido de estudiante y aprendizaje a lograr.

10. Malla curricular: La malla curricular de un sistema educativo opresor se caracteriza por:

a. Fragmentar el conocimiento en cursos o módulos independientes sin conexión horizontal y vertical en la malla. 
b. Omitir la incorporación de cursos que atiendan las necesidades de la población estudiantil desde una visión integral y holista.

c. Ausencia de flexibilidad curricular para la incorporación de cursos o asignaturas según necesidades de las poblaciones meta.

11. Áreas y ejes. El uso de áreas y ejes tienen como objetivo romper con la fragmentación tradicional del currículo y su plan de estudios; sin embargo, si se utiliza como formalidad sin implicaciones en la dinámica del desarrollo de cursos, permite repetir el enfoque fragmentado favorecedor del sistema educativo opresor.

12. Programas de cursos. Los programas de los cursos o asignaturas promueven un sistema educativo opresor si:

a. Cada programa se desarrolla de forma aislada por un especialista a cargo.

b. Los objetivos o propósitos visualizan el aprendizaje de forma acumulativa, fragmentada, controlable, medible y rígida.

c. Omiten elementos sustantivos como pensamiento crítico, investigación, habilidades blandas u otras; y si los toman en cuenta, es de forma fracturada y manifiesta solo en un apartado.

d. La selección y organización de contenidos omite responder a las necesidades de estudiantes, contexto y diversas realidades del proceso educativo.

e. Se presenta una sobrecarga de contenidos o competencias.

f. Centran las actividades de aprendizaje en dinámicas de enseñanza unidireccional.

g. Sostienen, implícitamente, un enfoque conductista del aprendizaje.

h. La mediación se concentra en actividades realizadas por la persona docente.

i. La mediación didáctica se presenta como activismo didáctico; es decir, se incluyen actividades innovadoras vinculadas en lo operativo con constructivismo, socioconstructivismo, complejidad y enfoque crítico pero vaciadas de procedimientos, metodología e implicaciones de cada sustento.

j. Se presenta una evaluación sumativa, fragmentada y unidireccional de los procesos de aprendizaje.

13. Contextualización curricular y el proyecto educativo. Se puede manifestar un sistema educativo opresor si:

a. Omite la participación (en el diseño curricular) de las personas docentes y estudiantes que implementarán el currículo.

b. Omite las realidades de infraestructura, equipo, mobiliario y recursos didácticos necesarias para la contextualización del diseño curricular.

c. Presenta una escasa o nula participación de docentes, estudiantes, familias y comunidad en la toma de decisiones como perfiles, selección y organización de contenidos, mediación, evaluación y acciones de mejora.

d. Existe un aislamiento del proceso educativo con respecto a las necesidades y realidades del entorno (comunal-local, regional, nacional y mundial).

e. Establece responsabilidades de gestión e implementación curricular desde una visión técnica y fragmentada. 
f. Omite incorporar una visión holista sobre la persona aprendiente y los mecanismos para incorporar sus realidades socioemocionales-afectivas en el proceso de aprendizaje.

g. Omite incorporar mecanismos para la actualización y transformación de la propuesta curricular ante las situaciones emergentes en la contextualización curricular, sean de procesos académicos o situaciones producidas por la estructura política, socioeconómica y cultural.

Los anteriores principios pueden ser incorporados en una revisión autocrítica por parte de las personas diseñadoras del currículo para establecer las posibilidades de mejora de la propuesta con respecto al objetivo de formar seres integrales en el marco de un compromiso pedagógico, ético y cultural.

Aunado a lo anterior, se debe explicitar que el cumplimiento de estas características (u otras indicadas por las personas gestoras) del diseño curricular para un sistema educativo opresor solo representa el interés de uno o varios grupos para la formación de personas esclavas, pero no se traduce en una determinante absoluta, en el tanto la contextualización curricular y, en especial, la interacción docenteestudiante o estudiante-docente con las realidades de su contexto social, cultural, político y económico constituyen la variable determinante para la concreción, o no, del proyecto educativo plasmado en el diseño curricular

\section{CONCLUSIONES}

Lo expuesto en este ensayo permite concluir que la interacción sociedad y educación es una fuente de reflexión-acción necesaria para las reformas curriculares, con especial atención a la interacción del modelo capitalista y proyectos hegemónicos con los objetivos educativos, diseño curricular y vivencia educativa. Al respecto, destaca la asociación del enfoque técnico del currículo y el modelo de producción capitalista, así como del modelo neoliberal y las reformas curriculares-educativas de finales del siglo XX con profundas implicaciones ontológicas.

En este contexto, el sistema educativo ha respondido de forma implícita a la premisa de formar personas esclavas en tiempos modernos, es decir, personas sometidas a un poder invisible con un proceso educativo que elimine o disminuya habilidades, destrezas, conocimientos y actitudes que favorecen la liberación, la realización plena y la construcción de un ser humano integral en convivencia. Con tal fin, la pedagogía crítica y el enfoque curricular crítico han elaborado un amplio capital académico sobre reflexiones-propuestas para la transformación de estas realidades.

En línea con la pedagogía crítica y el enfoque curricular crítico, se estableció una serie de principios y acciones de un diseño curricular que favorecería la construcción de un sistema educativo opresor y, por ende, formador de personas en esclavitud moderna. El establecer las características del diseño curricular opresor resulta relevante en aspectos del currículo como área de conocimiento para cuestionar prácticas y productos curriculares que se observan como normales en las diversas realidades nacionales, pero que ameritan una reflexión.

Por lo anterior, lo expuesto resulta relevante en el tanto es una propuesta pionera de principios para la detección de un currículo opresor en todas las etapas o componentes del diseño. Esta acción, construida desde la crítica, favorece la posible elaboración de otros posibles lineamientos o indicadores para la detección de estos diseños curriculares por parte de las personas gestoras, en apego a la postura del currículo crítico. Así, lo indicado en este ensayo no pretende ser de implementación taxativa ni limitante; por el contrario, es una invitación a la reflexión y transformación de la práctica curricular.

Aunado a lo anterior, al establecerse los lineamientos o características por cada etapa o componente del diseño curricular, el presente ensayo logra colocar premisas básicas de la pedagogía crítica en una sistematización con un enfoque y propuesta inéditas en los estudios curriculares de la región, favoreciendo 
un posible debate académico sobre la temática, la propuesta de lineamientos y, especialmente, el papel del diseño curricular en la gestación o implementación de sistemas educativos represores.

Finalmente, la propuesta invita a ampliar las investigaciones desde un enfoque crítico sobre la vinculación de los diseños del currículo con respecto a estructuras sociales, grupos de presión o interés y proyectos hegemónicos o de resistencia, así como la sistematización de estas influencias en los respectivos procesos de diseño, implementación y evaluación del currículo.

\section{REFERENCIAS}

Apple, M. (1996a). El conocimiento oficial. Barcelona: Paidós.

Apple, M. (1996b). Política cultural y Educación. Barcelona: Paidós.

Apple, M. (1997). Educación y poder. Barcelona: Paidós.

Cabello, M. (2003). Imaginar e instituir la educación globalizada. En: Martínez, J. (coord.) Ciudadanía, poder y educación. España: Graó.

Escudero, J. (Ed.). (2000). Diseño, desarrollo e innovación del currículum. Madrid: Síntesis Educativa.

Freire, P. (2015a). La pedagogía del oprimido. http://www.ensayistas.org/critica/liberacion/varios/ freire.pdf

Freire, P. (2015b). La educación como práctica de libertad. http://www.lugaradudas.org/pdf/ iconoclasistas_paulo_freire.pdf

Freire, P. (2012). Pedagogía de la indignación. Buenos Aires, Argentina: Siglo XXI.

Freire, P. (2008). Cartas a quien pretende enseñar. Buenos Aires, Argentina: Siglo XXI.

Freire, P. (2006). Pedagogía de la autonomía: Saberes necesarios para la práctica educativa. México, D.F.: Siglo XXI.

Freire, P. (2005a). Pedagogía del oprimido. México, D.F.: Siglo XXI.

Freire, P. (2005b). Cartas a quien pretende enseñar. México, D.F.: Siglo XXI.

Freire, P. (2005 c). Pedagogía de la esperanza. México, D.F.: Siglo XXI.

Freire, P. (2004a). El grito manso. México, D.F.: Siglo XXI.

Freire, P. (2001). Política y Educación. México, D.F.: Siglo XXI.

Freire, P. (1977). La educación como práctica de la libertad. México, D.F.: Siglo XXI.

Gimeno, J. (2010a). ¿Qué significa el currículum?. En Gimeno, J. (comp.), Saberes e incertidumbres sobre el currículum (pp. 21-44). Madrid: Morata.

Gimeno, J. (2010b). El currículum en la sociedad de la información y del conocimiento. En: Gimeno, J. (comp), Saberes e incertidumbres sobre el currículum (pp. 180- 202). Madrid: Morata.

Gimeno, J. (2001). El currículum: una reflexión sobre la práctica. España: Morata.

Gimeno, J. (2000). Diseño del currículum, diseño de la enseñanza. El papel de los profesores. En José Gimeno y Ángel Pérez, Comprender y transformar la enseñanza (pp. 227-266). Madrid: Morata.

Gimeno, J. (1997). La pedagogía por objetivos: Obsesión por la eficiencia. Madrid: Morata.

Giroux, H. (2006). La escuela y la lucha por la ciudadanía. Pedagogía crítica de la época moderna. México, D.F.: Siglo XXI.

Giroux, H. (2003). Teoría y resistencia en educación. México, D.F.: Siglo XXI. 
Giroux, H. (1997). Cruzando los límites. Trabajadores culturales y políticas educativas. Barcelona: Paidós.

Giroux, H. (1990). Los profesores como intelectuales. Barcelona: Paidós.

Giroux, H. y McLaren, P. (1998). Lenguaje, escolarización y subjetividad: más allá de una pedagogía de reproducción y resistencia. En Giroux, H. y McLaren, P., Sociedad, cultura y educación (pp. 75-103). Madrid: Niño y Dávila Editores.

Hinkelammert, F. (1999). El Huracán de la globalización. Costa Rica: Departamento Ecuménico de Investigaciones.

Kemmis, S. (1998). El currículum: más allá de la teoría de la reproducción. Madri: Morata.

McLaren, P. (1997). Pedagogía crítica y cultura depredadora. Barcelona: Paidós.

Santos, M. (2003). Arte y Parte. Desarrollar la democracia en las escuelas. Madrid: Homo Sapiens.

Santos, M. (1999). Democracia escolar o el problema de la nieve frita. En: Manzano, Pablo (Coord.), Volver a pensar la educación. Madrid: Morata.

Magendzo, A. (2008). Dilemas del currículum y la pedagogía. Santiago: LOM Ediciones.

Manzano, P. (coord.). Volver a pensar la educación (pp. 128-141). Madrid: Morata.

Santos, M. (1995). La evaluación: un proceso de diálogo, comprensión y mejora. Madrid: Aljibe.

Taba, H. (1974). Elaboración del currículo. Teoría y práctica. Buenos Aires, Argentina: Troquel.

Tamayo, J. (2003). Ética liberadora del cristianismo frente a teología neoliberal del mercado. Senderos, 25, pp. $743-795$.

Torres, J. (2001). Educación en tiempos del neoliberalismo. Madrid: Morata.

Torres, J. (1998). El currículum oculto. Madrid: Morata.

Toruño, C. (2020a). Propuesta sistematizada para la evaluación de estructuras curriculares. El caso de la Universidad Técnica Nacional. Yulök Revista de Innovación Académica, 3(2), 29-43. https://doi. org/10.47633/yulk.v3i2

Toruño, C. (2020b). El currículum en el contexto costarricense: propuesta de definiciones para su conceptualización. Revista Ensayos Pedagógicos, 15(1), 39-59. https://doi.org/10.15359/rep.15-1.2

Toruño, C. (2010). Fundamentos curriculares de la ciudadanía en un Estado neoliberal: el caso del sistema educativo costarricense. Revista electrónica Actualidades Investigativas en Educación, 10(2), 1-25. https://revistas.ucr.ac.cr/index.php/aie/article/view/10132

Tyler, R. (1973). Principios básicos del currículum. Buenos Aires, Argentina: Troquel.

Vargas, L. (2002). Costa Rica, 1985-1997: liberalización y ajuste estructural o la autodestrucción del neoliberalismo. Costa Rica: EUNED. 